\title{
Extraction and Characterization of Lipopolysaccharide from Salmonella typhi Nilima Patel
}

The Patidar Gin Science College, Bardoli, Gujarat India

\section{Article Info}

Volume 8, Issue 1

Page Number: 236-242

\section{Publication Issue :}

January-February-2021

\section{Article History}

Accepted : 08 Feb 2021

Published : 18 Feb 2021

\section{ABSTRACT}

There is no standard process available for high purity LPS isolation, and it may be appropriate to mix two purification steps. For Salmonella typhi LPS that were subjected to normal microbiological \& biochemical screening protocols, updated phenol-water extraction protocol \& non-phenolic extraction methods were also used in present research. Pellet of crude LPS obtained with wet weight was $2.0 \mathrm{gm}$. yield of LPS was more by hot phenol method $1.94 \mathrm{mg} / \mathrm{ml}$ as compared to non-phenolic method $0.40 \mathrm{mg} / \mathrm{ml}$. relative purity of LPS obtained by hot phenol method was more as compared to non-phenolic method, as protein content was $23.60 \mathrm{mg} / \mathrm{ml}$ in LPS extracted from hot phenol method \& $26.62 \mathrm{mg} / \mathrm{ml}$ in LPS extracted from non-phenolic method. However, Nucleic acid contain was comparable in LPS extracted from both methods. Qualitative analysis showed ladder like bands of LPS extracted by hot phenol method as compared to single band obtained for LPS extracted by non-phenolic method. Findings of silver staining clearly revealed ladder pattern of multi-rung bands that are characteristics of smooth form of gram negative bacteria due to difference in length of carbohydrate chain of O-antigen component. In order to clarify diseased conditions \& better work on LPS profiling, this research may be crucial to lead to more successful diagnosis and care.

Keywords: Bacteria, Extraction, Lipopolysaccharide, Phenol, Salmonella typhi

\section{INTRODUCTION}

Enteric fever refers to as severe typhoid \& paratyphoid. It is popularly referred to as typhoid fever. Most common etiological agents of enteric fever are Salmonella enterica serotype typhi \& Salmonella enterica serotype paratyphi [1]. For humans, typhoid fever is unique. Paratyphoid fever, which is similar to typhoid fever, but is milder disease $\&$ is caused by other, serotypes of Salmonella, such as
Salmonella paratyphi A, Salmonella paratyphi B \& Salmonella hirchfeldi. These fevers are also called enteric fevers [2]. Genus Salmonella belonging to family Enterobacteriaceae. Organisms are noncapsulating, non-sporulating, Gram-negative facultative anaerobic Bacilli with characteristics of flagellar, somatic \& external coat antigens \& characteristics of $\mathrm{O}, \mathrm{H}, \mathrm{VI}$ [3]. Via oral-fecal pathway, Salmonella is spread primarily by consuming inadequately cooked food \& food items infected with 
Salmonella bacteria. Because of swift \& widespread appearance of S. Typhoid serotypes are becoming more difficult to detect $\&$ treat, with susceptibility to numerous antibiotics \& changing forms of bacterial appearance. $[4,5]$.

As with other gram negative Bacilli, terms from cytoplasmic membrane to outer membrane are expanded by cell envelope of Salmonella . Lipid bilayer comprising phospholipids, proteins, lipoproteins \& lipopolysaccharide is outer membrane. In part, permeability of outer membrane is due to collectively named porins of Omp. Porin is particularly immunogenic Salmonella Omp. Lipopolysaccharide (LPS) is complex structure that is released on cell lysis which can act as endotoxin in this moiety \& is essential in deciding organism's virulence. There are three components of LPS: exterior layer of O-polysaccharides, middle section (core polysaccharides) \& inner lipid - A. In pathogenesis, LPS segment is essential, evoking fever, activating complement pathway, kinin systems \& altering role of lymphocytes [6]. Lipid is heavily retained \& exerts endotoxic action, while carbohydrate antigen chain "O" is repeating oligosaccharide polymer that varies between organisms \& is responsible for bacterial serological specificity. [7]. Pathophysiological symptoms such as fever, leukopenia, leukocytosis \& reactivity of Schwartzman [8, 9] are caused by LPS. Identification of very powerful causative role of LPS in diseases caused by gram negative bacteria led several researchers to perform studies aimed at isolating \& purifying it. Not unexpectedly, many methods \& protocols have been implemented to separate \& purify LPS from bacteria, including trichloro acetic acid extraction at 4oC [10], aqueous butanol [11], triton/ $\mathrm{Mg}+2$ [12], cold $\mathrm{EtOH}$ [13], \& $\mathrm{H} 2 \mathrm{O}$ extraction at $100 \mathrm{oC}$ [14]. Phenol, chloroform, petroleum-ether [15] \& $\mathrm{MeOH}$ [16] purification protocols are explicitly defined for rough LPS. For purification of LPS from E.coli [17], variation of Westphal process based on hot phenol extraction protocol \& scale exclusion chromatography has been successfully used recently. Because of its high yield, process suggested by Westphal [18] is still most frequent technique used for LPS extraction. Protein \& nucleic acid contamination is one of key drawbacks of certain suggested LPS purification procedures that obstruct reliable implementation of final product in such sensitive tests as molecular \& immunological experiments. While it is possible to use ultracentrifugation to remove contaminating proteins, [18], this typically contributes to lower yields \& LPS soil is polluted by large concentrations of nucleic acids [15]. In this opinion, no single procedure is suitable for high purity LPS isolation \& combination of two purification steps may be needed. Updated phenol-water extraction protocol \& non-phenolic extraction of LPS from Salmonella typhi extracted \& characterized from isolates that have been subjected to normal microbiological \& biochemical screening processes were used in present research.

\section{METHODS AND MATERIAL}

\section{Bacteria \& Culture Conditions}

Salmonella typhi has been collected from Chandigarh, India, MTCC. As recommended by MTCC, it was retained as pure culture on Medium 3 \& was periodically resurrected by successive transfers on same medium. In $10 \mathrm{ml}$ of Luria Bertanni Broth, typhi was inoculated \& incubated overnight at $37^{\circ} \mathrm{C} .5 \mathrm{ml}$ of culture grown overnight was inoculated in 1 lit. Flask holding $500 \mathrm{ml}$ of $\mathrm{LB}$ broth \& incubated overnight at $37^{\circ} \mathrm{C}$ on incubator shaker at $180 \mathrm{rpm}$. At final concentration of 1 percent, 37 percent formaldehyde was applied to culture broth \& culture was held for cell inactivation at RT for 24 hours. Cells were extracted \& washed twice with phosphate buffered saline by centrifugation (pH 7.2). Cells were extracted by centrifugation \& weighed by wet cell weight. 


\section{LPS Extraction}

LPS extraction from culture isolates was done by following methods Hot Phenol water method [15] \& Chloroform-Methanol method [19].

\section{Hot Phenol Water Method}

LPS estimation was done by Westphal et al., with modifications. Nutrient broth was inoculated with Salmonella typhi \& kept for incubation at $37{ }^{\circ} \mathrm{C}$ for 48 hr to obtain logarithmic growth. It was then centrifuged at $5000 \mathrm{rpm}$ for $30 \mathrm{mins}$. The wet weight of pellet obtained was 2gms. It was homogenized in demineralized water so as to obtain suspension of 10 $\mathrm{ml}$. Volume of $90 \%$ phenol solution equal to that of suspension was prepared. two solutions, preheated to $67^{\circ} \mathrm{C} \pm 2^{\circ} \mathrm{C}$ are then mixed \& left for $15 \mathrm{mins}$ at $67^{\circ} \mathrm{C}$ with vigorous stirring. Mixture was transferred into glass centrifuge tubes, which are placed in ice until two phases have separated, before being centrifuged at 5000 rpm for $30 \mathrm{mins}$ at $\pm 4{ }^{\circ} \mathrm{C}$.

The aqueous phase (supernatant) is collected \& stored at $\pm 4{ }^{\circ} \mathrm{C}$. Phenolic phase, which is under interface, was also removed for purpose of second extraction. For this second extraction, volume of dematerialized water, preheated to $67^{\circ} \mathrm{C}$, that is equal to that of phenolic phase is added. This mixture was maintained at $67{ }^{\circ} \mathrm{C}$ for $15 \mathrm{mins}$ with vigorous stirring. Centrifuge at 5000rpm for $30 \mathrm{mins}$. Cells were extracted \& washed twice with phosphate buffered saline by centrifugation ( $\mathrm{pH}$ 7.2). Cells were extracted by centrifugation, \& mea was wet weight of cells. First aqueous phase was applied to this aqueous phase. Aqueous process was dialyzed until phenol odor vanished against purified water \& then against milliQ-water. Dialysis membrane filled with crude LPS extract was placed in unionized water for dialysis \& left overnight. Phenol content in water was monitored by measuring absorbance at $260 \mathrm{~nm}$.

\section{Chloroform-Methanol Method}

LPS extraction was done following method given by Mirzaei, A., et al [19] with modification. Suspension colonies of bacteria were moved into test tubes. This sample was then centrifuged at 2500 to $3000 \mathrm{rpm}$ for 30 min. supernatant was discarded after centrifuging. $2 \mathrm{ml}$ (95 percent) of alcohol was applied to sedimentpossessing test tube. This test tube was centrifuged at $2000 \mathrm{rpm}$ for $10 \mathrm{~min}$. Supernatant was discarded \& 2 $\mathrm{ml}$ of alcohol cleaned sediment. Three times, this process was repeated. Sediment was finally combined with alcohol \& centrifuged at $2000 \mathrm{rpm}$ for 10 minutes. Supernatant has been discarded \& sand has been dried. 1ml EDTA 10 percent re-suspended dry bacterium. It was then sonicated. $1 \mathrm{ml}$ of saturated methanol/chloroform (1:2 ratio) was applied to bacterium-EDTA solution \& shackled for 2 hours after centrifugation at $2000 \mathrm{rpm}$ for $10 \mathrm{~min}$. Three layers were created \& new tube divided top \& bottom layers. They were left to evaporate entirely \& dried pellet contained Salmonella typhi LPS, which was quantitatively \& qualitatively further studied.

\section{Estimation of LPS}

Thiobarbituric acid assays have been used to assess concentration of LPS in aqueous phases [9]. Using LPS derived from $\mathrm{S}$, regular curve was prepared. Typhos (Sigma). On $25 \mu$ LPS solutions each containing 5, 10, 15, 20 \& $25 \mu \mathrm{g}$ LPS, LPS analysis was performed. At $548 \mathrm{~nm}$, absorbance against blanks containing all other reagents except LPS was measured.

\section{Estimation of protein}

Protein estimation was conducted as per micro assay method of Bradford as provided in instruction manual.

\section{Estimation of Nucleic acid}

Aqueous phase $1 \& 2$ absorbance was measured at 260 $\mathrm{nm}$ in UV visible spectrophotometer against blank distilled water. absorbance was multiplied by 40 to get $\mu \mathrm{g} / \mathrm{ml}$ RNA concentration. 


\section{SDS-PAGE for LPS}

Sodium dodecyl sulfate-polyacrylamide gel (SiscoResearch Laboratories Pvt. Ltd.) containing 04\% \& $12 \%$ acrylamide for stacking \& separating gel respectively, was prepared \& electrophoresis (Bio-Rad) was conducted at $30 \mathrm{~mA}$ until front of tracking dye bromophenol blue is few $\mathrm{mm}$ from bottom.

The silver \& Coomassie blue staining dotted SDSPAGE fractionated LPS preparations. According to previously mentioned methods of silver staining[21] \& normal Coomassie blue staining, SDS-PAGE fractionated LPS preparations is stained according to [22].

\section{III.RESULTS}

\section{Purity \& Yield of LPS Analysis Derived by Hot} Phenol Process

In present study we obtained pellet of crude LPS with wet weight of $2.0 \mathrm{gm}$. After hot phenol water extraction which was dissolved in phenol in equal volume of suspension. amount of aqueous phase correspondingly obtained was $20-25 \mathrm{ml}$, which was subjected to dialysis (Figure1) to obtain relatively pure LPS. Dialysis was done till smell of phenol was completely gone, which was checked by taking absorbance of dialysate at $260 \mathrm{~nm}$.

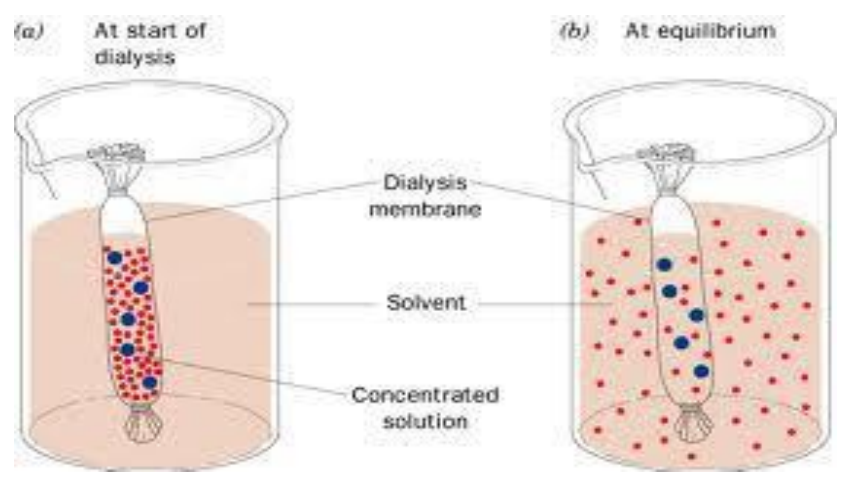

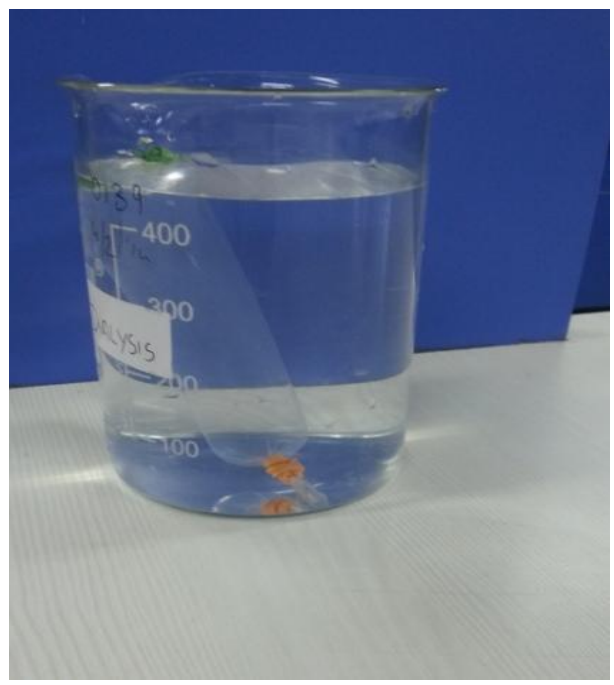

Figure 1: Dialysis of crude LPS extracted from S. typhi

The LPS, thus obtained was then estimated using thiobarbituricmethod as per protocol [23].

TABLE I

ESTIMATION FROM LPS EXTRACTED FROM S. TYPHI

\begin{tabular}{|l|l|l|l|l|l|l|}
\hline $\begin{array}{l}\text { Meth } \\
\text { od }\end{array}$ & $\begin{array}{l}\text { Amt } \\
\text { of } \\
\text { med } \\
\text { ia } \\
\text { (ml) }\end{array}$ & $\begin{array}{l}\text { No. of } \\
\text { coloni } \\
\text { es } \\
\text { inocul } \\
\text { ated }\end{array}$ & $\begin{array}{l}\text { Bacte } \\
\text { rial } \\
\text { pellet } \\
\text { (wet } \\
\text { weig } \\
\text { ht })\end{array}$ & $\begin{array}{l}\text { Amt. } \\
\text { of } \\
\text { aque } \\
\text { ous } \\
\text { phas } \\
\text { e }\end{array}$ & $\begin{array}{l}\text { O. } \\
\text { D. } \\
\text { at } \\
548 \\
\text { nm }\end{array}$ & $\begin{array}{l}\text { LPS } \\
\text { estima } \\
\text { ted } \\
(\mathrm{mg} / \mathrm{m}\end{array}$ \\
$\mathbf{l})$
\end{tabular}

\section{Protein Estimation}

In order to check purity of LPS extracted by above mentioned two methods, protein estimation \& nucleic acid estimation was done as per standard protocols. Results of protein estimations are shown in Table No. 2. 
TABLE III

PROTEIN ESTIMATION LPS EXTRACTED FROM S. TYPHI

\begin{tabular}{|c|c|c|}
\hline Method & O.D. at 595nm & $\begin{array}{c}\text { Conc. of protein } \\
(\mu \mathrm{g} / \mathrm{ml})\end{array}$ \\
\hline Hot phenol & 0.360 & 23.60 \\
\hline $\begin{array}{c}\text { Non } \\
\text { phenolic }\end{array}$ & 0.406 & 26.62 \\
\hline
\end{tabular}

\section{Nucleic Acid Estimation}

Results of nucleic acid estimation which was done as per protocol given by Sambrook [24] are shown in Table \& 18. OD of 1 corresponds to $50 \mu \mathrm{g} / \mathrm{ml}$ for DNA $\& 40 \mu \mathrm{g} / \mathrm{ml}$ for RNA.

\section{Analysis of Purity \& Yield of LPS Extracted by Non- Phenolic Method}

Extraction of rough LPS was done as per protocol by Darveau et al. [25]. Bacterial sediment obtained was dissolved in $2 \mathrm{ml}$ Alcohol each tube. 0.86-1.09gms pellets were dissolved in $40 \mathrm{ml}$ of EDTA. Amount of Bacterial-EDTA suspension obtained was $20-25 \mathrm{ml}$. wet weight of pellet obtained \& amount of LPS estimated is shown in Table 1.

\section{Quantitative Analysis of LPS Extracted by Non- Phenolic Method}

In order to check purity of LPS extracted by above mentioned two methods, protein estimation \& nucleic acid estimation was done as per standard protocols. Results of protein estimations are shown in Table 2.

Nucleic acid estimation was done as per standard protocol [24]. OD of 1 corresponds to $50 \mu \mathrm{g} / \mathrm{ml}$ for DNA \& $40 \mu \mathrm{g} / \mathrm{ml}$ for RNA.

\section{Qualitative Analysis of Purity of LPS}

SDS-PAGE \& silver staining (Ag) of Salmonella typhi by standard protocol [26] qualitatively tested purity of LPS samples collected. Samples of LPS stained with $\mathrm{Ag}$ staining solution showed up to $6 \mathrm{kDa}$ of heavy stained bands. Effect of LPS periodic acid oxidation in

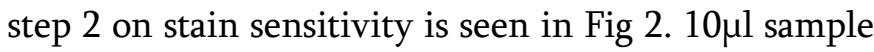
was inoculated, revealing clear band of up to $6 \mathrm{kDa}$ in all samples.

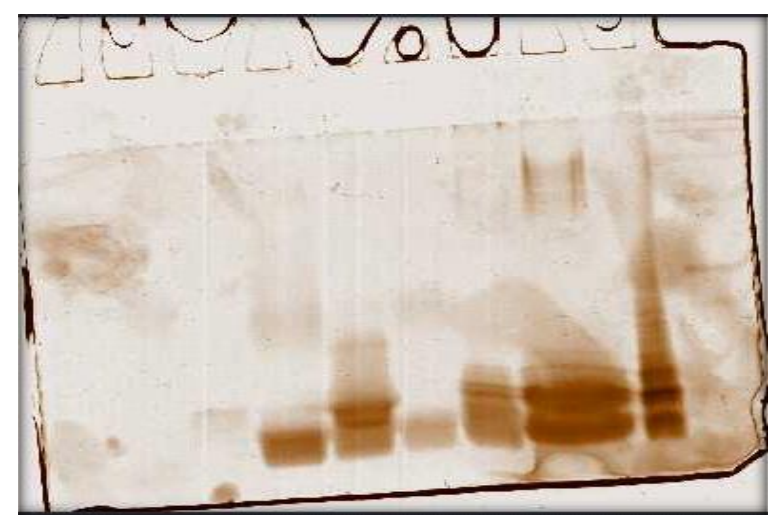

Figure 2: SDS PAGE \& silver staining analysis of Salmonella typhi LPS (Lan1 1- Protein marker, 2LPS standard, 3 \& 4- LPS Non phenolic Method, 5 to

7- LPS Hot phenol method 8-to 10- Blank)

SDS-PAGE was characterized by purified LPSs accompanied by silver \& commassive blue staining \& HPLC. Findings of silver staining clearly revealed ladder pattern of multi-rung bands that are characteristics of smooth form of gram negative bacteria due to difference in length of carbohydrate chain of O-antigen component. Based on appearance or absence of ladder like structure, LPS may be graded as either smooth or rough form [27, 28]. Owing to absence of ' $O$ ' basic chain containing repeated units of oligopolysaccharides, rugged shape of LPS does not have ladder-like structure.

\section{IV.DISCUSSION}

A major component of gram negative bacteria's outer membrane is lipopolysaccharides. They are endotoxic in nature \& are also one of principal antigens against which antibody reaction during infection is mounted. It is responsible for pathological symptoms of gramnegative bacterial infections. LPS study reveals that molecule's architectural components are: (I) lipophilic 
lipid consisting of phosphorylated disaccharide attached to hydroxylated or non-hydroxylated fatty acids, (ii) short-length central oligosaccharide, \& (iii) replicated units of specific oligosaccharides showing chemical \& serological determinants for recognition of organisms \& strains in outermost O-specific side chain. Some approaches are technically or instrumentally demanding, \& thus simple, costeffective \& accurate methods of isolating pure LPS will be of great benefit at same time. In present analysis, these two methods have been used for extraction \& purification of LPS with certain modifications.

Blood culture isolates obtained from referral hospital was screened as per standard protocol. Salmonella typhi were microbiologically \& biochemically characterized. LPS from Salmonella typhi was estimated by hot phenol method \& non-phenolic method. yield of LPS was more by hot phenol method $1.94 \mathrm{mg} / \mathrm{ml}$ as compared to non-phenolic method 0.40 $\mathrm{mg} / \mathrm{ml}$. relative purity of LPS obtained by hot phenol method was more as compared to non-phenolic method, as protein content was $23.60 \mathrm{mg} / \mathrm{ml}$ in LPS extracted from hot phenol method \& $26.62 \mathrm{mg} / \mathrm{ml}$ in LPS extracted from non-phenolic method. However, Nucleic acid contain was comparable in LPS extracted from both methods. Qualitative analysis showed ladder like bands of LPS extracted by hot phenol method as compared to single band obtained for LPS extracted by non-phenolic method.

\section{CONCLUSION}

In conclusion, this research may be essential for identifying diseased conditions \& future studies on LPS profiling, which will lead to diagnosis \& care more effectively.

\section{REFERENCES}

[1]. Khoharo, H.K. \& I.A. Memon, Drug Resistance Patterns of Salmonella e Enterica Serotype Typhi \& Paratyphi at Tertiary Care Hospital of Sindh, Pakistan. JMED Research, 2014.

[2]. Crump, J.A., S.P. Luby, \& E.D. Mintz, global burden of typhoid fever. Bulletin of World Health Organization, 82: p. 346-353, 2004.

[3]. Shahane, V., et al., Correspondence-Non-typhoid Salmonellosis: Emerging infection in Pune? Indian journal of medical microbiology, 25(2): p. 173-174, 2007.

[4]. Dougan, G. \& S. Baker, Salmonella enterica serovar Typhi \& pathogenesis of typhoid fever. Annual review of microbiology, 68: p. 317-336. 2014.

[5]. Akinyemi, K., et al., Multidrug resistance in Salmonella enterica serovar typhi isolated from patients with typhoid fever complications in Lagos, Nigeria. Public health, 119(4): p. 321-327. 2005.

[6]. Shnyra, A., M. Luchi, \& D.C. Morrison, Preparation of endotoxin from pathogenic Gram-negative bacteria, in Septic Shock Methods \& Protocols. Springer. p. 13-25. 2000.

[7]. Erridge, C., E. Bennett-Guerrero, \& I.R. Poxton, Structure \& function of lipopolysaccharides. Microbes \& infection, 4(8): p. 837-851. 2002.

[8]. Luderitz, O., et al., Lipid A: chemical structure \& biological activity. Journal of Infectious Diseases, 128(Supplement_1): p. S17-S29. 1973.

[9]. Galanos, C., et al., Biological activities of lipid complexed with bovine-serum albumin. European Journal of Biochemistry, 31(2): p. 230-233. 1972.

[10].Staub, A., Removeal of protein-Sevag method. Methods Carbohydr. Chem., 5: p. 5-6. 1965.

[11].Morrison, D.C. \& L. Leive, Fractions of lipopolysaccharide from Escherichia coli O111: B4 prepared by two extraction procedures. Journal of Biological Chemistry, 250(8): p. 2911-2919. 1975.

[12]. Delahooke, D., G. Barclay, \& I. Poxton, Tumor necrosis factor induction by aqueous phenolextracted lipopolysaccharide complex from 
Bacteroides species. Infection \& immunity, 63(3): p. 840-846. 1995.

[13]. Sonesson, A., et al., Chemical composition of lipopolysaccharide from Legionella pneumophila. Archives of microbiology, 153(1): p. 72-78. 1989.

[14]. Eidhin, D.N. \& C. Mouton, rapid method for preparation of rough \& smooth lipopolysaccharide from Bacteroides, Porphyromonas \& Prevotella. FEMS microbiology letters, 110(2): p. 133-138. 1993.

[15].Galanos, C., O. Luderitz, \& O. Westphal, new method for extraction of $\mathrm{R}$ lipopolysaccharides. European Journal of Biochemistry, 9(2): p. 245-249. 1969.

[16]. Nurminen, M. \& M. Vaara, Methanol extracts LPS from deep rough bacteria. Biochemical \& biophysical research communications, 219(2): p. 441-444. 1996.

[17].Alvarez-Suarez, J.M., et al., Anti-inflammatory effect of Capuli cherry against LPS-induced cytotoxic damage in RAW 264.7 macrophages. Food \& chemical toxicology, 102: p. 46-52. 2017.

[18].Jann, K., et al., Immunochemical studies of $\mathrm{K}$ antigens from Escherichia coli. II. $\mathrm{K}$ antigen from E. coli 08: K42 (A): H. Biochemische Zeitschrift, 342(1): p. 1-22. 1965.

[19]. Mirzaei, A., et al., simple method for non phenolic extraction of lipopolysaccharide from Salmonella typhimurium \& Salmonella enteritidis with high purity \& pyrogenicity in rat. Scientific Research \& Essays, 6(5): p. 1101-1105. 2011.

[20]. Westphal, O. \& K. Jann, Bacterial lipopolysaccharides: extraction with phenol water \& further applications of procedure. Methods Carbohydr. Chem. 5: 83-91. 1965.

[21]. Fomsgaard, A., M. Freudenberg, \& C. Galanos, Modification of silver staining technique to detect lipopolysaccharide in polyacrylamide gels. Journal of clinical microbiology, 28(12): p. 2627-2631. 1990.

[22].Sedmak, J.J. \& S.E. Grossberg, rapid, sensitive, \& versatile assay for protein using Coomassie brilliant blue G250. Analytical biochemistry, 79(1-2): p. 544-552. 1977.
[23].Nakamura, S., et al., roles of quorum-sensing system in release of extracellular DNA, lipopolysaccharide, \& membrane vesicles from Pseudomonas aeruginosa. Japanese journal of infectious diseases, 61(5): p. 375-378. 2008.

[24]. Russell, D.W. \& J. Sambrook, Molecular cloning: laboratory manual.: Cold Spring Harbor Laboratory Cold Spring Harbor, NY. Vol. 1. 2001

[25]. Darveau, R.P. \& R. Hancock, Procedure for isolation of bacterial lipopolysaccharides from both smooth \& rough Pseudomonas aeruginosa \& Salmonella typhimurium strains. Journal of bacteriology, 155(2): p. 831-838. 1983.

[26].Tsai, C.-M. \& C.E. Frasch, sensitive silver stain for detecting lipopolysaccharides in polyacrylamide gels. Analytical biochemistry, 119(1): p. 115-119. 1982.

[27].Hitchcock, P.J. \& T.M. Brown, Morphological heterogeneity among Salmonella lipopolysaccharide chemotypes in silver-stained polyacrylamide gels. Journal of bacteriology, 154(1): p. 269-277. 1983.

[28].Kido, N., M. Ohta, \& N. Kato, Detection of lipopolysaccharides by ethidium bromide staining after sodium dodecyl sulfate-polyacrylamide gel electrophoresis. Journal of bacteriology, 172(2): p. 1145-1147. 1990.

\section{Cite this article as :}

Nilima Patel, "Extraction and Characterization of Lipopolysaccharide from Salmonella typhi ", International Journal of Scientific Research in Science and Technology (IJSRST), Online ISSN : 2395-602X, Print ISSN : 2395-6011, Volume 8 Issue 1, pp. 236-242, January-February 2021. Available at doi $\quad$ : https://doi.org/10.32628/IJSRST218122 Journal URL : https://ijsrst.com/IJSRST218122 